\title{
Spatiotemporal dynamics of the kinetic energy in the atmospheric boundary layer from minisodar measurements
}

\author{
Alexander Potekaev ${ }^{1}$, Liudmila Shamanaeva ${ }^{1,2, *}$ and Valentina Kulagina ${ }^{3}$ \\ Tomsk State University; potekaev@spti.tsu.ru \\ Institute of Atmospheric Optics SB RAS; sima@iao.ru \\ Siberian State Medical University; kulagina.vv@mail.ru \\ Correspondence: sima@iao.ru
}

Abstract: Spatiotemporal dynamics of the atmospheric kinetic energy and its components caused by the ordered and turbulent motions of air masses are estimated from minisodar measurements of three velocity vector components and their variances within the lowest 5-200 m layer of the atmosphere, with a particular emphasis on the turbulent kinetic energy. The layered structure of the total atmospheric kinetic energy has been established. From the diurnal hourly dynamics of the altitude profiles of the turbulent kinetic energy (TKE) retrieved from minisodar data, four layers are established by the character of the altitude TKE dependence, namely, the near-ground layer, the surface layer, the layer with a linear TKE increase, and the transitive layer above. In the first layer, the most significant changes of the TKE were observed in the evening hours. In the second layer, no significant changes in the TKE values were observed. A linear increase in the TKE values with altitude was observed in the third layer. In the fourth layer, the TKE slightly increased with altitude and exhibited variations during the entire observation period. The altitudes of the upper boundaries of these layers depended on the time of day.

The MKE values were much less than the corresponding TKE values, they did not exceed $50 \mathrm{~m}^{2} / \mathrm{s}^{2}$. From two to four MKE layers were distinguished based on the character of its altitude dependence. The two-layer structures were observed in the evening and at night (under conditions of the stable atmospheric boundary layer). In the morning and daytime, the four-layer MKE structures with intermediate layers of linear increase and subsequent decrease in the MKE values were observed. Our estimates demonstrated that the TKE contribution to the total atmospheric kinetic energy considerably (by a factor of 2.5-3) exceeded the corresponding MKE contribution.

Keywords: atmospheric boundary layer, spatiotemporal dynamics of the atmospheric kinetic energy, turbulence, minisodar measurements

\section{Introduction}

Kinetic energy of the atmospheric boundary layer (ABL) is the energy of the moving air masses. It determines the momentum, heat and moisture transfer through the ABL. Dependig on the space and time averaging, it is subdivided into two components: the mean kinetic energy associated with the average wind velocity and the turbulent kinetic energy associated with the wind velocity variance [1-3]. A number of remote sensing methods of the wind velocity have been developed with application of lidars, radars, and sodars [4-7]. Thus, in [8] a coherent wind lidar was used to study the spatiotemporal distribution of the wind velocity and its variance in the stable atmospheric boundary layer at altitudes of 100-500 m. The SLODAR method [9-11] of remote determination of the wind speed and turbulent characteristics above large telescopes in the daytime should also be mentioned here.

However, only sodars allow three wind vector components to be measured together with their variances to retrieve the total kinetic energy in the $\mathrm{ABL}$, including the turbulent and mean kinetic energy components. Depending 
on the sounding frequency, sodars are subdivided into conventional sodars with working frequencies of $1-2 \mathrm{kHz}$ sounding range of 50-1000 m, and spatial resolution of 20-30 m and minisodars with working frequencies of 3-10 kHz, sounding range of 5-200 $\mathrm{m}$, and spatial resolution up to $5 \mathrm{~m}$. It should be noted that the minisodars have a number of advantages over the above-considered methods of remote sensing of the wind vector components and its variance, first of all, they have smaller overall dimensions, smaller minimal sounding altitude (5-10 m), higher spatial resolution $(5 \mathrm{~m})$, and higher pulse repetition period (up to $4 \mathrm{~s}$ ). In addition, the Doppler minisodars allow very long time series of continuous round-the-clock measurements of the wind vector components and their variances to be obtained to analyze the long-term spatiotemporal dynamics of the atmospheric kinetic energy.

In the present work, we study the diurnal hourly dynamics of the atmospheric kinetic energy and its components in the ABL at altitudes of 5-200 m from measurements of the velocity vector components and their variances using the commercially available triaxial Doppler monostatic minisodar AV4000 (Atmospheric Systems Corporation) [12]. In Section 2, the applied approach is described. In Section 3, the diurnal hourly dynamics of the turbulent kinetic energy component is analyzed. The spatiotemporal dynamics of the mean kinetic energy component is studied in Section 4. An analysis of the relative contributions of the turbulent and mean kinetic energy components to the total atmospheric kinetic energy is analyzed in Section 5. The results obtained are discussed in Section 6 followed by the Section Conclusion.

\section{Applied approach}

At present, many works are devoted to sodar applications for measuring wind vector components in the ABL [7, 13]. Much less works consider algorithms of big sodar data processing. While processing real data of minisodar measurements in the ABL, we also faced the big data problem. A very large volume of inhomogeneous measurement data and a presence of outliers excluded their manual adjustment. In [14-17] we have developed a special program of sodar data preprocessing based on sensoring of data samples to eliminate the oulliers using the pendulum truncation algorithm and presented some results of analysis of the spatiotemporal dynamics of the kinetic wind energy in the ABL.

In the present work, we first study the diurnal hourly dynamics of the turbulent and mean kinetic energy components in the atmospheric boundary layer at altitudes of 5-200 m based on postprocessing of the big volume of data measured with a commercial triaxial Doppler monostatic minisodar AV4000 (Atmospheric system Corporation) [12]. The minisodar AV4000 was equipped with a solar cell and a 50-element phased antenna array forming tree independent beams one vertical and two tilted at angles of $18^{\circ}$ to the vertical in two mutually orthogonal planes. The antenna array was used to both transmit and receive backscattered acoustic signals. Minisodar pulses with a frequency of $4900 \mathrm{~Hz}$ and duration of $60 \mathrm{~ms}$ were periodically transmitted at the above-indicated zenith angles to the atmosphere every $4 \mathrm{~s}$. The vertical profiles of the wind vector components were calculated from the Doppler frequency shifts measured in three receiving channels and calculated from the well-known formulas. The lowest minisodar measurement altitude was $5 \mathrm{~m}$; its vertical resolution was $\Delta z=5 \mathrm{~m}$. The design and operation principle of the AV4000 minisodar are described in detail in [12].

We processed measurements performed in the vicinity of Santa Clarita, California, USA, with the AV4000 minisodar from 12 till 17 September, 2006 [18]. The measurement site was relatively level, with no pronounced highs or lows, without high vegetation. The weather was dry, warm, and sunny. The measurement series from $N=150$ profiles were processed, which provided $10 \mathrm{~min}$ averaging of the results obtained. 
The kinetic energy in the $\mathrm{ABL} E_{\Sigma}=m V^{2} / 2$ is determined by the energy of motion of air masses - the wind velocity. Below we present the kinetic energy in the ABL reduced to unit air mass $E=E_{\Sigma} / m$ and measured in $\mathrm{m}^{2} / \mathrm{s}^{2}$ $\left(\mathrm{m}^{2} / \mathrm{s}^{2}=\mathrm{J} / \mathrm{kg}\right)$ [1-3]. It is natural that the regularities in the spatiotemporal behavior of the reduced kinetic energy will fully concern the total kinetic energy. For this reason, below we use the term kinetic energy for the kinetic energy per unit air mass. It is equal to the sum of two components: the mean kinetic energy EMKE, associated with the average wind velocity, and the turbulent kinetic energy ETKE, associated with the wind velocity variance. It is written in the form [14-17]

$$
\begin{gathered}
E(z, t)=\left(E_{\mathrm{MKE}}(z, t)+E_{\mathrm{TKE}}(z, t)\right) / m=0.5\left(\bar{V}_{x}^{2}(z, t)+\bar{V}_{y}{ }^{2}(z, t)+\bar{V}_{z}^{2}(z, t)\right) \\
+0.5\left(\sigma_{x}^{2}(z, t)+\sigma_{y}^{2}(z, t)+\sigma_{z}^{2}(z, t)\right)
\end{gathered}
$$

where $\bar{V}_{x}(z, t), \bar{V}_{y}(z, t)$, and $\bar{V}_{z}(z, t)$ are the average wind vector components at altitude $z$ at time $t$ and $\sigma_{x}^{2}(z, t), \sigma_{y}^{2}(z, t)$, and $\sigma_{z}^{2}(z, t)$ are their variances. In this case, expressions in the parentheses in the right-hand side of Eq. (1) determine $E_{\mathrm{MKE}}(z, t)$ and $E_{\mathrm{TKE}}(z, t)$, respectively. The components $E_{\operatorname{MKE}}\left(z_{j}, t_{k}\right)$ and $E_{\mathrm{TKE}}\left(z_{j}, t_{k}\right)$ in the $j$ th strobe, $j=1$, ..., 150 of the $k$ th measurement series started at time $t_{k}$ were calculated from the preprocessed data samples with eliminated outliers from the formulas [14-17]

$$
\begin{gathered}
E_{\mathrm{MKE}}\left(z_{j}, t_{k}\right)=0.5\left[\left\langle V_{x}\left(z_{j}, t_{k}\right)\right\rangle^{2}+\left\langle V_{y}\left(z_{j}, t_{k}\right)\right\rangle^{2}+\left\langle V_{z}\left(z_{j}, t_{k}\right)\right\rangle^{2}\right] \\
=\frac{0.5}{N^{2}}\left[\left(\sum_{i=1}^{N} V_{x i j}\left(z_{j}, t_{k}\right)\right)^{2}+\left(\sum_{i=1}^{N} V_{y i j}\left(z_{j}, t_{k}\right)\right)^{2}+\left(\sum_{i=1}^{N} V_{z i j}\left(z_{j}, t_{k}\right)\right)^{2}\right], \\
E_{\mathrm{TKE}}\left(z_{j}, t_{k}\right)=0.5\left(\sigma_{x}^{2}\left(z_{j}, t_{k}\right)+\sigma_{y}^{2}\left(z_{j}, t_{k}\right)+\sigma_{z}^{2}\left(z_{j}, t_{k}\right)\right) \\
=\frac{0.5}{N^{2}}\left[\left(\sum_{i=1}^{N} V_{x i j}\left(z_{j}, t_{k}\right)-\left\langle V_{x}\left(z_{j}, t_{k}\right)\right\rangle\right)^{2}+\sum_{i=1}^{N}\left(\left(V_{y i j}\left(t_{k}\right)\right)-\left\langle V_{y}\left(z_{j}, t_{k}\right)\right\rangle\right)^{2}+\sum_{i=1}^{N}\left(\left(V_{z i j}\left(t_{k}\right)\right)-\left\langle V_{z}\left(z_{j}, t_{k}\right)\right\rangle\right)^{2}\right],
\end{gathered}
$$

where $V_{m i j}\left(z_{j}, t_{k}\right), m=x, y, z$, are the wind vector components measured with the minisodar in the $j$ th range gate centered at altitude $z_{j}$ in the $k$ th series of minisodar measurements started at time $t_{k},\left\langle V_{m}\left(z_{j}, t_{k}\right)\right\rangle$ are their 10 -min averages, and $\sigma_{m}^{2}\left(z_{j}, t_{k}\right)$ are their variances.

\section{Diurnal hourly dynamics of the turbulent kinetic energy}

Figure 1 shows the diurnal hourly dynamics of the turbulent kinetic energy retrieved from minisodar measurements on September 16, 2006 using formula (3). From Fig. 1, four layers are clearly distinguished by the character of the altitude TKE dependence, namely, near-ground layer I with the upper boundary at the altitude 

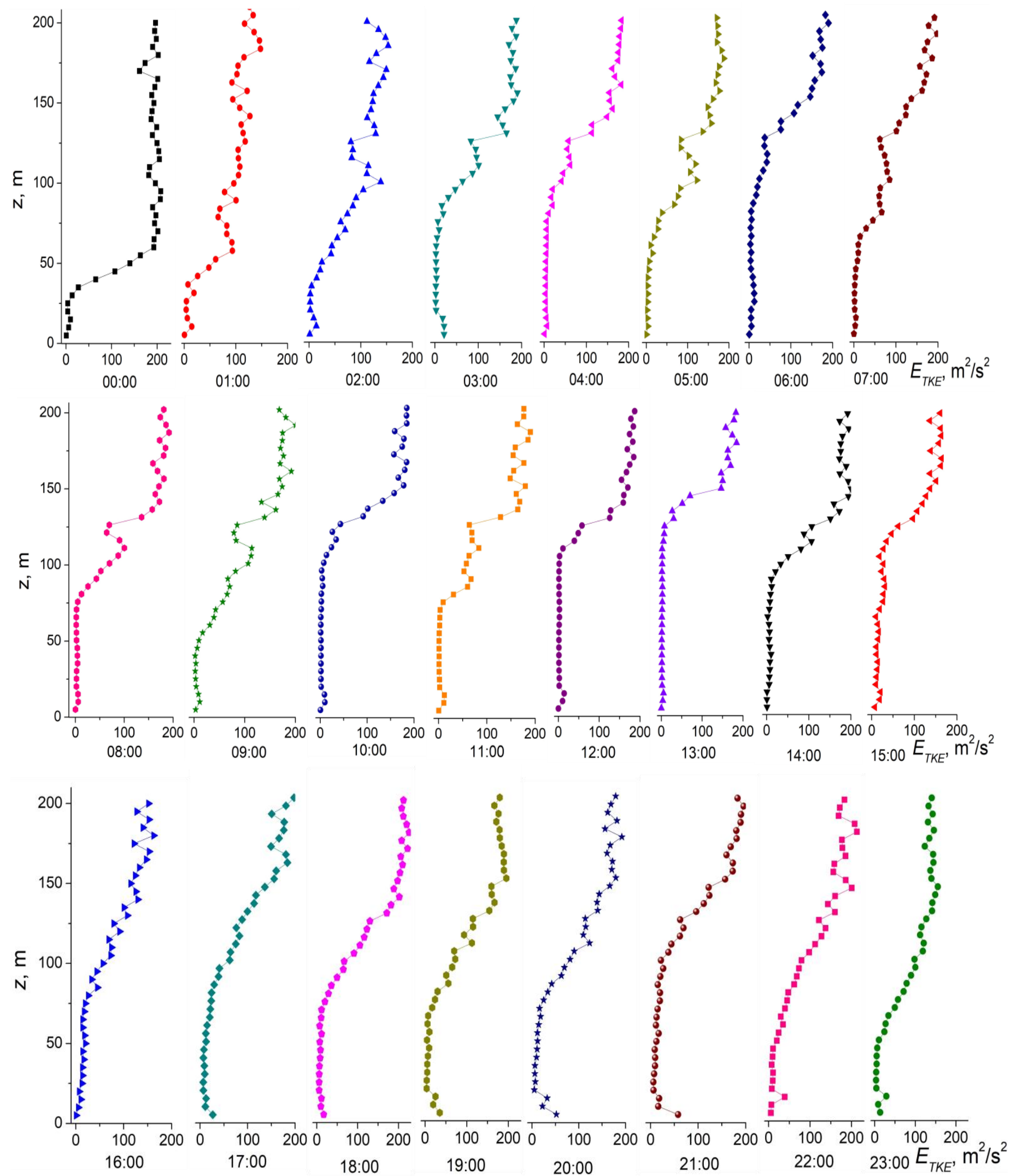

Fig. 1. Diurnal hourly dynamics of the turbulent kinetic energy component retrieved from minisodar measurements with 10-min averaging. The start local time of mesaurement series is indicated in the lower right corner of the of the plots. 
$z_{\mathrm{IT}}=10-20 \mathrm{~m}$, surface layer II with $z_{\mathrm{IIT}}=25-172 \mathrm{~m}$, layer III of linear TKE increase to $z_{\mathrm{IIIT}}=70-185 \mathrm{~m}$, and transitive layer IV above. In the near-ground layer, the TKE first slightly increased with altitude from $3 \mathrm{~m}^{2} / \mathrm{s}^{2}$ at the lowest measurement altitude to $16-20 \mathrm{~m}^{2} / \mathrm{s}^{2}$ from 00:00 till 16:00; in the afternoon, from 17:00 till 21:00, the maximum TKE value reached already $50 \mathrm{~m}^{2} / \mathrm{s}^{2}$ and started to decrease with altitude; the most significant changes of the TKE in layer I were observed in the evening hours (from 17:00 till 21:00), during which the TKE decreased with altitude from $60 \mathrm{~m}^{2} / \mathrm{s}^{2}$ in the first measurement altitude to about $6 \mathrm{~m}^{2} / \mathrm{s}^{2}$. In layer II, no significant changes in the TKE values were observed, but the altitudes of its lower and upper boundaries varied significantly with the time of day. In layer III, the TKE values linearly increased with altitude irrespective of the time of day, from $2.2-54.7 \mathrm{~m}^{2} / \mathrm{s}^{2}$ at its lower boundary to $100.5-200.1 \mathrm{~m}^{2} / \mathrm{s}^{2}$ at the upper boundary. In transitive layer IV, the TKE changed insignificantly. In Table 1 below, the diurnal hourly variations of the altitudes of the upper boundaries of these layers and the TKE values at these altitudes are presented. The TKE values at the lowest measuring altitude $z_{\min }=5 \mathrm{~m}$ and at the maximum measuring altitude $z_{\max }=200 \mathrm{~m}$ are also given in the table.

Table 1. Diurnal hourly variations of the altitudes of the three upper layer boundaries and the TKE values at these altitudes.

\begin{tabular}{|c|c|c|c|c|c|c|c|c|}
\hline Local time & $\mathbf{0 0 : 0 0}$ & $\mathbf{0 1 : 0 0}$ & $\mathbf{0 2 : 0 0}$ & $\mathbf{0 3 : 0 0}$ & $\mathbf{0 4 : 0 0}$ & $\mathbf{0 5 : 0 0}$ & $\mathbf{0 6 : 0 0}$ & $\mathbf{0 7 : 0 0}$ \\
\hline$T K E_{5}, \mathrm{~m}^{2} / \mathrm{s}^{2}$ & 0.7 & 0.6 & 1.2 & 21.0 & 0.9 & 0.4 & 0.6 & 0.2 \\
\hline$z_{\mathrm{IT}}, \mathrm{m}$ & 15 & 10 & 20 & 15 & 10 & 10 & 20 & 15 \\
\hline$T K E_{z_{\mathrm{IT}}}, \mathrm{m}^{2} / \mathrm{s}^{2}$ & 9.8 & 14.8 & 2.2 & 18 & 6.8 & 3.7 & 4.7 & 5.0 \\
\hline$z_{\mathrm{IIT}}, \mathrm{m}$ & 35 & 25 & 35 & 65 & 75 & 50 & 80 & 60 \\
\hline$T K E_{z_{\mathrm{IIT}}}, \mathrm{m}^{2} / \mathrm{s}^{2}$ & 27.2 & 4.44 & 54.7 & 5.1 & 6.0 & 7.1 & 5.0 & 10.6 \\
\hline$z_{\mathrm{IIIT}}, \mathrm{m}$ & 70 & 85 & 100 & 170 & 175 & 185 & 165 & 165 \\
\hline$T K E_{z_{\text {IIIT }}}, \mathrm{m}^{2} / \mathrm{s}^{2}$ & 201.5 & 100.5 & 138.4 & 186.1 & 175.1 & 170.7 & 174.1 & 172.5 \\
\hline$T K E_{200}, \mathrm{~m}^{2} / \mathrm{s}^{2}$ & 196.3 & 126.4 & 112.1 & 187.7 & 182.8 & 170.5 & 182.6 & 191.5 \\
\hline
\end{tabular}

\begin{tabular}{|c|c|c|c|c|c|c|c|c|}
\hline Local time & $\mathbf{0 8 : 0 0}$ & $\mathbf{0 9 : 0 0}$ & $\mathbf{1 0 : 0 0}$ & $\mathbf{1 1 : 0 0}$ & $\mathbf{1 2 : 0 0}$ & $\mathbf{1 3 : 0 0}$ & $\mathbf{1 4 : 0 0}$ & $\mathbf{1 5 : 0 0}$ \\
\hline$T K E_{5}, \mathrm{~m}^{2} / \mathrm{s}^{2}$ & 0.2 & 3.3 & 0.5 & 0.4 & 0.3 & 0.1 & 0.6 & 7.4 \\
\hline$z_{\mathrm{IT}}, \mathrm{m}$ & 15 & 20 & 20 & 20 & 20 & 20 & 20 & 20 \\
\hline$T K E_{z_{\mathrm{IT}}}, \mathrm{m}^{2} / \mathrm{s}^{2}$ & 5.4 & 4.3 & 2.1 & 2.5 & 2.0 & 2.1 & 6.0 & 9.7 \\
\hline$z_{\text {IIT }}, \mathrm{m}$ & 75 & 40 & 95 & 70 & 105 & 125 & 90 & 105 \\
\hline$T K E_{z_{\text {IIT }}}, \mathrm{m}^{2} / \mathrm{s}^{2}$ & 4.9 & 2.2 & 3.2 & 3.2 & 3.0 & 7.8 & 11.0 & 18.0 \\
\hline$z_{\mathrm{IIIT}}, \mathrm{m}$ & 140 & 160 & 150 & 135 & 150 & 155 & 150 & 155 \\
\hline$T K E_{z_{\text {IIIT }}}, \mathrm{m}^{2} / \mathrm{s}^{2}$ & 172.1 & 192.2 & 178.0 & 164.1 & 170.0 & 150.1 & 200.1 & 151.0 \\
\hline$T K E_{200}, \mathrm{~m}^{2} / \mathrm{s}^{2}$ & 181 & 168.3 & 184.6 & 176.8 & 186.9 & 182.6 & 192.1 & 160.5 \\
\hline
\end{tabular}

\begin{tabular}{|c|c|c|c|c|c|c|c|c|}
\hline Local time & $\mathbf{1 6 : 0 0}$ & $\mathbf{1 7 : 0 0}$ & $\mathbf{1 8 : 0 0}$ & $\mathbf{1 9 : 0 0}$ & $\mathbf{2 0 : 0 0}$ & $\mathbf{2 1 : 0 0}$ & $\mathbf{2 2 : 0 0}$ & $\mathbf{2 3 : 0 0}$ \\
\hline$T K E_{5}, \mathrm{~m}^{2} / \mathrm{s}^{2}$ & 0.9 & 26.6 & 16.7 & 35.04 & 51.9 & 57.8 & 5.3 & 13.5 \\
\hline$z_{\mathrm{IT}}, \mathrm{m}$ & 20 & 20 & 20 & 20 & 20 & 20 & 20 & 20 \\
\hline$T K E_{z_{\mathrm{IT}}}, \mathrm{m}^{2} / \mathrm{s}^{2}$ & 6.9 & 6.7 & 5.8 & 3.4 & 4.7 & 6.4 & 7.6 & 4.0 \\
\hline$z_{\mathrm{IIT}}, \mathrm{m}$ & 75 & 60 & 70 & 65 & 70 & 100 & 45 & 50 \\
\hline$T K E_{z_{\text {IIT }}}, \mathrm{m}^{2} / \mathrm{s}^{2}$ & 19.7 & 14.6 & 11.5 & 7.2 & 16.0 & 22.0 & 10.7 & 10.3 \\
\hline
\end{tabular}




\begin{tabular}{|c|c|c|c|c|c|c|c|c|}
\hline$z_{\text {IIIT }}, \mathrm{m}$ & 170 & 160 & 160 & 135 & 150 & 160 & 145 & 145 \\
\hline$T K E_{z_{\text {IIIT }}, \mathrm{m}^{2} / \mathrm{s}^{2}}$ & 153.1 & 183.7 & 210 & 166.7 & 179.1 & 172.9 & 200.6 & 155.3 \\
\hline$T K E_{200}, \mathrm{~m}^{2} / \mathrm{s}^{2}$ & 151.8 & 197.8 & 212.2 & 179.2 & 178.9 & 182.7 & 183 & 140.4 \\
\hline
\end{tabular}

From the table it follows that the upper boundary of the near-ground layer (layer I) was in the range 10-20 m, and the TKE value in this layer was in the range 2.2-18.00 during the entire observation period. The maximum TKE value in layer II was $54.7 \mathrm{~m}^{2} / \mathrm{s}^{2}$ at night, then in the morning and daytime from 03:00 till 13:00, it decreased to $2.2-11.00 \mathrm{~m}^{2} / \mathrm{s}^{2}$. In the evening and night hours, it increased again to $7.2-22.0 \mathrm{~m}^{2} / \mathrm{s}^{2}$. The upper boundary of layer II incerased from $70 \mathrm{~m}$ at night to $185 \mathrm{~m}$ in the morning at 05:00 (sunrise), and then remained in the range 135-170 $\mathrm{m}$. In this layer, the TKE values remained practically independent of the altitude. In layer III, the linear increase of the TKE values with altitude was observed during the entire measurement period, irrespective of the time of day. In layer IV, the TKE slightly increased with altitude and exhibited fine structural changes during the entire observation period.

\section{Diurnal hourly dynamics of the mean kinetic energy component}

Figure 2 shows the diurnal hourly dynamics of the mean kinetic energy component MKE retrieved from minisodar measurements on September 16, 2006 using formula (2). As above, we first analyze its altitude behavior. It can be seen that the MKE values are much less than the corresponding TKE values, they did not exceed $50 \mathrm{~m}^{2} / \mathrm{s}^{2}$. Several MKE layers can be distinguished based on the character of the its altitude dependence. During the entire period of observation, near-ground layers I to altitudes $z_{\mathrm{IM}}=10-25 \mathrm{~m}$ are clearly distinguished in which the MKE value decreased. Above this layer, the patterns of the altitude behavior of the MKE value differed depending on the time of day. At night, from 01:00 till 02:00, the MKE values decreased with altitude. Then in the morning, MKE layers II and III appeared at 03:00 and were observed till 14:00, in which the MKE values fist linearly increased, reached their maximum at the upper boundary $z_{\mathrm{IIM}}$ of layer II, and then linearly decreased in layer III. Layer IV above was characterized by clearly pronounced fluctuations of the MKE values and the general trend of the MKE decrease with altitude. In the evening and at night, from 15:00 till the end of the observation period, only MKE layers I and IV above were detected.

In Table 2 below, the diurnal hourly variations of the altitudes of the upper boundaries of these layers and the MKE values at these altitudes are presented. For altitude profiles comprising only two MKI layers I and IV, in the corresponding column of Table 2, marked by the asterisk, we presented the MKE values at altitudes of 100 and $150 \mathrm{~m}$. Attention is drawn to the vertical profiles marked by two asterisks: they had the layers with increased MKE values at altitudes of $155-200 \mathrm{~m}$ (at 16:00 with $M K E=13.2-3.0 \mathrm{~m}^{2} / \mathrm{s}^{2}$ ), 120-185 m (at 18:00 with $M K E=52.0-22.0 \mathrm{~m}^{2} / \mathrm{s}^{2}$ ), and 120$200 \mathrm{~m}$ (at 23:00 with $M K E=22.0-4.0 \mathrm{~m}^{2} / \mathrm{s}^{2}$ ). From the table it can be seen that the maximum MKE values (up to $52.8 \mathrm{~m}^{2} / \mathrm{s}^{2}$ at 02:00) were observed at the minimal sensing altitude. The two-layered structures (indicated by asterisks) were observed in the evening and at night. The layers with increased MKE values (indicated by two asterisks) were observed at altitudes of $175-200 \mathrm{~m}$ at 16:00 with $M K E_{\max }=13.3 \mathrm{~m}^{2} / \mathrm{s}^{2} ; 140-185 \mathrm{~m}$ at $18: 00$ with $M K E_{\max }=52.5 \mathrm{~m}^{2} / \mathrm{s}^{2}$; and $120-200 \mathrm{~m}$ at 23:00 with $M K E_{\max }=22.4 \mathrm{~m}^{2} / \mathrm{s}^{2}$. In the morning and daytime, the four-layer MKE structures were observed.

The similar behavior of the kinetic energy components was pointed out in [3] from the results of measurements with a FAS64 sodar in three altitude ranges $z=20-50,50-80$, and $80-110 \mathrm{~m}$. According to [3], the diurnal behavior of the kinetic energy was characterized by the presence of minima and maxima. It is obvious that the time of their occurrence and their values depend on the meteorological conditions of observations, characteristics of cloudiness, and solar radiation intensity. It should also be noted that the layered structure of the atmospheric turbulence was 
pointed out in [11], in which the maximum changes of the turbulence layer strengths were observed in the lower layer of the atmosphere at altitudes up to $70 \mathrm{~m}$, and the diurnal variations of their altitudes were also indicated.
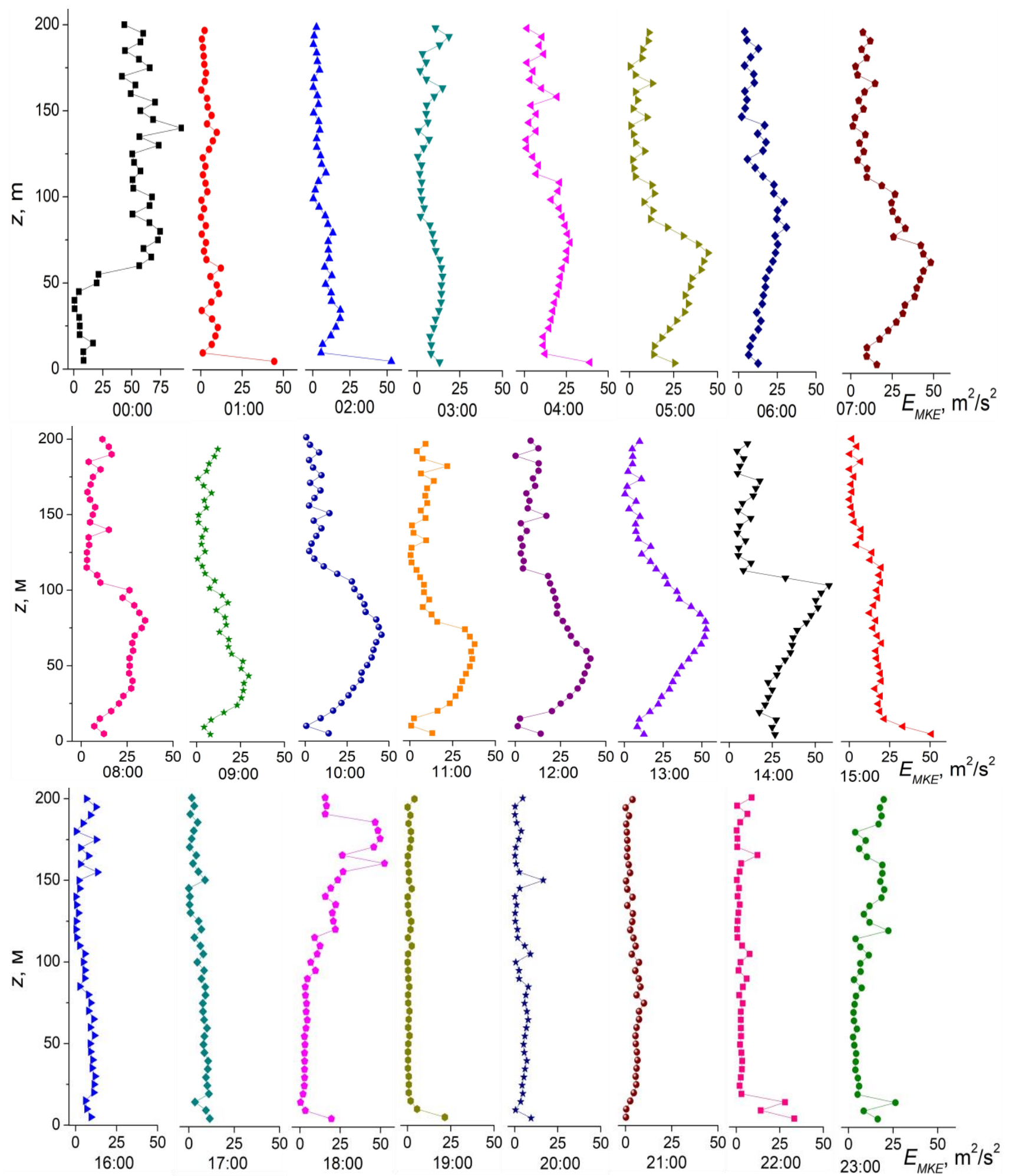

Fig. 2. Diurnal hourly dynamics of the mean kinetic energy retrieved from minisodar measurements with $10-$ min averaging. The start time of the 10-min measurement series is indicated in the lower right corner of the plots. 
Table 2. Diurnal hourly variations of the altitudes of the three upper layer boundaries and the MKE values at these altitudes.

\begin{tabular}{|c|c|c|c|c|c|c|c|c|}
\hline Local time & $\mathbf{0 0 : 0 0}$ & $\mathbf{0 1 : 0 0}$ & $\mathbf{0 2 : 0 0}$ & $\mathbf{0 3 : 0 0}$ & $\mathbf{0 4 : 0 0}$ & $\mathbf{0 5 : 0 0}$ & $\mathbf{0 6 : 0 0}$ & $\mathbf{0 7 : 0 0}$ \\
\hline$M K E_{5}, \mathrm{~m}^{2} / \mathrm{s}^{2}$ & 8.4 & 4.5 & 52.8 & 13.2 & 39.0 & 25.5 & 12.6 & 15.7 \\
\hline$z_{\mathrm{IM}}, \mathrm{m}$ & 40 & 10 & 15 & 20 & 20 & 15 & 10 & 15 \\
\hline$M K E_{z_{\mathrm{IM}}}, \mathrm{m}^{2} / \mathrm{s}^{2}$ & 0.6 & 1.2 & 6.6 & 7.6 & 11.2 & 14.0 & 6.6 & 9.7 \\
\hline$z_{\mathrm{IIM}}, \mathrm{m}$ & 140 & 100 & 100 & 100 & 130 & 125 & 125 & 125 \\
\hline$M K E_{z_{\text {IIM }}}, \mathrm{m}^{2} / \mathrm{s}^{2}$ & 93.0 & 0.3 & 0.3 & 2.8 & 1.3 & 1.7 & 5.8 & 4.1 \\
\hline$z_{\mathrm{IIIM}}, \mathrm{m}$ & 200 & 150 & 150 & 150 & 160 & 150 & 150 & 150 \\
\hline$M K E_{z_{\text {IIIM }}}, \mathrm{m}^{2} / \mathrm{s}^{2}$ & 43.6 & 6.5 & 0.5 & 5.4 & 19.5 & 10.0 & 2.0 & 2.5 \\
\hline$M K E_{200}, \mathrm{~m}^{2} / \mathrm{s}^{2}$ & 43.6 & 2.3 & 2.4 & 10.8 & 1.53 & 11.0 & 4.0 & 7.3 \\
\hline
\end{tabular}

\begin{tabular}{|c|c|c|c|c|c|c|c|c|}
\hline Local time & $\mathbf{0 8 : 0 0}$ & $\mathbf{0 9 : 0 0}$ & $\mathbf{1 0 : 0 0}$ & $\mathbf{1 1 : 0 0}$ & $\mathbf{1 2 : 0 0}$ & $\mathbf{1 3 : 0 0}$ & $\mathbf{1 4 : 0 0}$ & $\mathbf{1 5 : 0 0}$ \\
\hline$M K E_{5}, \mathrm{~m}^{2} / \mathrm{s}^{2}$ & 12.3 & 7.7 & 14.0 & 13.1 & 14.0 & 12.6 & 26.6 & 50.8 \\
\hline$z_{\mathrm{IM}}, \mathrm{m}$ & 10 & 10 & 10 & 15 & 15 & 10 & 20 & 25 \\
\hline$M K E_{z_{\mathrm{IM}}}, \mathrm{m}^{2} / \mathrm{s}^{2}$ & 7.1 & 4.2 & 0.6 & 2.4 & 2.6 & 8.3 & 17.5 & 17.9 \\
\hline$z_{\mathrm{IIM}}, \mathrm{m}$ & 80 & 125 & 125 & 130 & 115 & 125 & 115 & 100 \\
\hline$M K E_{z_{\text {IIM }}}, \mathrm{m}^{2} / \mathrm{s}^{2}$ & 34.8 & 0.5 & 2.4 & 1.0 & 4.3 & 11.1 & 8.2 & 16.9 \\
\hline$z_{\mathrm{IIIM}}, \mathrm{m}$ & 115 & 150 & 150 & 150 & 150 & 150 & 150 & 150 \\
\hline$M K E_{z_{\text {IIIM }}}, \mathrm{m}^{2} / \mathrm{s}^{2}$ & 2.9 & 1.0 & 14.5 & 9.1 & 17.2 & 10.1 & 12.4 & 1.9 \\
\hline$M K E_{200}, \mathrm{~m}^{2} / \mathrm{s}^{2}$ & 11.5 & 12.0 & 0.6 & 9.2 & 8.5 & 9.8 & 10.6 & 1.5 \\
\hline
\end{tabular}

\begin{tabular}{|c|c|c|c|c|c|c|c|c|}
\hline Local time & $\mathbf{1 6 : 0 0 * *}$ & $\mathbf{1 7 : 0 0}^{*}$ & $\mathbf{1 8 : 0 0 * *}$ & $\mathbf{1 9 : 0 0}$ & $\mathbf{2 0 : 0 0}$ & $\mathbf{2 1 : 0 0}$ & $\mathbf{2 2 : 0 0 ^ { * }}$ & $\mathbf{2 3 : 0 0 ^ { * * }}$ \\
\hline$M K E_{5}, \mathrm{~m}^{2} / \mathrm{s}^{2}$ & 9.4 & 11.5 & 19.5 & 21.6 & 9.5 & 0.2 & 33.3 & 16.4 \\
\hline$z_{\mathrm{IM}}, \mathrm{m}$ & 15 & 15 & 15 & 20 & 10 & 10 & 15 & 20 \\
\hline$M K E_{z_{\mathrm{IM}}}, \mathrm{m}^{2} / \mathrm{s}^{2}$ & 6.0 & 3.4 & 0.3 & 0.8 & 0.4 & 0.3 & 3.0 & 5.1 \\
\hline$z_{\mathrm{IIM}}, \mathrm{m}$ & 100 & 100 & 160 & 100 & 100 & 100 & 100 & 100 \\
\hline$M K E_{z_{\text {IIM }}}, \mathrm{m}^{2} / \mathrm{s}^{2}$ & 4.7 & 4.7 & 52 & 0.1 & 0.6 & 7.3 & 2.5 & 6.6 \\
\hline$z_{\mathrm{IIIM}}, \mathrm{m}$ & 150 & 150 & 185 & 150 & 150 & 150 & 150 & 150 \\
\hline$M K E_{z_{\text {IIIM }}}, \mathrm{m}^{2} / \mathrm{s}^{2}$ & 2.0 & 8.9 & 46.6 & 0.9 & 16.5 & 0.3 & 0.4 & 17.8 \\
\hline$M K E_{200}, \mathrm{~m}^{2} / \mathrm{s}^{2}$ & 6.5 & 1.6 & 15.6 & 4.1 & 4.7 & 3.8 & 8.8 & 19.8 \\
\hline
\end{tabular}

5. Analysis of relative contributions of the turbulent and mean kinetic energy components to the total kinetic energy

Let us now estimate the relative contributions of the TKE and MKE components to the total kinetic energy. First of all, attention is drawn to the fact that the TKE values considerably exceeded the corresponding MKE values. If the first values reached and even exceed $200 \mathrm{~m}^{2} / \mathrm{s}^{2}$ (for example, at 00:00, from 05:000 till 14.00, and from 17.00 till 22.00), the MKE values, as a rule, hardly reached 50-70 $\mathrm{m}^{2} / \mathrm{s}^{2}$ (for example, at 00:00, from 13:00 till 15:00, and at 18:00). The TKE values exceeded the MKE values by a factor of 2.5-3. From here their prevalent contribution to the total kinetic energy follows.

At midnight, the maximum MKE and TKE values are observed. At altitudes up to 30-40 m, their values were low; however, at 40-60 m they both linearly increased. At higher altitudes, both components changed insignificantly with altitude; however, they changed considerably for the neighboring range gates. After midnight (at 01:00 and 
02:00), the MKE increased to $45-55 \mathrm{~m}^{2} / \mathrm{s}^{2}$ in the near-ground layer. When the altitude increased to $10-15 \mathrm{~m}$, the $\mathrm{MKE}$ values decreased to several fractions of $\mathrm{m}^{2} / \mathrm{s}^{2}$, which was accompanied by their considerable spreading. At the same time, the TKE values remained low up to 30-40 m, but at altitudes of 40-76 m, they linearly increased to 100$140 \mathrm{~m}^{2} / \mathrm{s}^{2}$. At higher altitudes, significant spreading of their values was also observed. The ratios $E_{\text {MKE }} / E_{\text {TKE }}$ at these night hours remained practically independent of the altitude.

From 03:00 till 14:00, the character of the altitude dependences remained unchanged. The MKE values in the first layer (up to 10-15 m) were low. Then up to 50-100 m, the MKE values increased (to $45-55 \mathrm{~m}^{2} / \mathrm{s}^{2}$ ) and then significantly decreased to $0.3-5 \mathrm{~m}^{2} / \mathrm{s}^{2}$, which was accompanied by their noticeable changes for the neighboring range gates. During the same period, the TKE values remained low up to 75-125 m. With further increase in altitude up to $150 \mathrm{~m}$, the TKE values linearly increased. It should be noted that during this period, an interesting peculiarity in their mutual behavior was observed: in the near-ground layer up to 15-20 m, the MKE and TKE values were very low. When the altitude increased to 50-100 m, the MKE values increased, whereas the TKE values decreased down to several fractions of $\mathrm{m}^{2} / \mathrm{s}^{2}$. At higher altitudes, the MKE values linearly decreased with altitude, while the TKE values linearly increased. Their ratios at altitudes from $15 \mathrm{~m}$ to $50-70 \mathrm{~m}$ first increased to $6-20$, then decreased to altitudes of 100 $120 \mathrm{~m}$, and remained practically constant at higher altitudes.

From 15:00 till 23:00, their mutual behavior changed. In the first layer, the MKE values were within 10-50 $\mathrm{m}^{2} / \mathrm{s}^{2}$, and the TKE values were only several fractions of $\mathrm{m}^{2} / \mathrm{s}^{2}$ up to 50-100 $\mathrm{m}$. When the altitude increased to $75-100 \mathrm{~m}$, the TKE values linearly increased. In the same altitude range during the same time period, the character of the MKE altitude dependence changed. Whereas from 15:00 till 17:00 the MKE values decreased with increasing altitude, at 18:00 the MKE values were only several fractions of $\mathrm{m}^{2} / \mathrm{s}^{2}$ and subsequently increased with altitude undergoing large variations. At 19:00, the MKE values were very low above the first layer. From 20:00 till 21:00, the MKE values linearly increased to $100 \mathrm{~m}^{2} / \mathrm{s}^{2}$, undergoing significant variations. In these evening hours, the ratios $E_{M K E} / E_{\text {TKE }}$ remained independent of altitude. Based on the foregoing analysis, we conclude that the TKE contribution to the total kinetic energy considerably (by a factor of 2.5-3) exceeded the corresponding MKE contribution.

\section{Discussion of results}

Results of measurements on September 12,14, 15, and 16 demonstrated that the observation time influenced significantly the results obtained. Thus, at the same altitudes at night (from 01:00 till 05:00), the kinetic energy did not exceed $20 \mathrm{~J} / \mathrm{m}^{3}$, and then it increased with observation time (from 20 to $50 \mathrm{~J} / \mathrm{m}^{3}$ ). From 05:00 till 12:00, the maximum turbulent energy was observed (sunrise at $~ 05: 00$ ). We consider that this was caused by heating of the Earth surface cooled at night. It is interesting that after sunrise, from 05:00 till 07:00, a fast change (a decrease) of the turbulent kinetic energy was observed. Then the system underlying surface - near-ground air layer approached its equilibrium state. As a consequence, the range of variations of the turbulent energy decreased. The most essential changes were observed at altitudes of 100-200 m. It is important that at altitudes up to $50-100 \mathrm{~m}$, the time of day had no significant influence on the results of observations, because at these altitudes, the turbulent kinetic energy was low and changed only weakly. Irrespective of the time of day, the maximum turbulent energy was observed at altitudes of 100-200 m.

From Eq. (3) it follows that the behavior of the mean kinetic energy component in the ABL is determined by the spatiotemporal dynamics of the wind vector. The diurnal hourly dynamics of the wind velocity in the vector representation on September 16 is shown in Fig. 3, with the magnitude of the vector at the point $(z, t)$ indicating the average wind velocity modulus and the direction of the vector indicating the direction of the average wind velocity. The measurement session started at 10:00 and ended at 23:00 on September 16. As can be seen from the figure, the direction of the average wind velocity did not experience sharp changes from layer to layer up to altitudes of $\sim 100 \mathrm{~m}$. 
However, the situation changed significantly in the altitude range from 100 to $200 \mathrm{~m}$. In this altitude range, the direction of motion of air masses experienced perturbations. Whereas they were observed at altitudes above $150 \mathrm{~m}$ at 10:00, by 14:00 their lower horizon approached $200 \mathrm{~m}$. With further increase in the observation time, the lower horizon of turbulent wind velocity perturbations repeatedly decreased. The repeated decrease of the lower horizon of the turbulent wind velocity fluctuations from 16:00 till 17:00 can also be seen in Fig. 3.

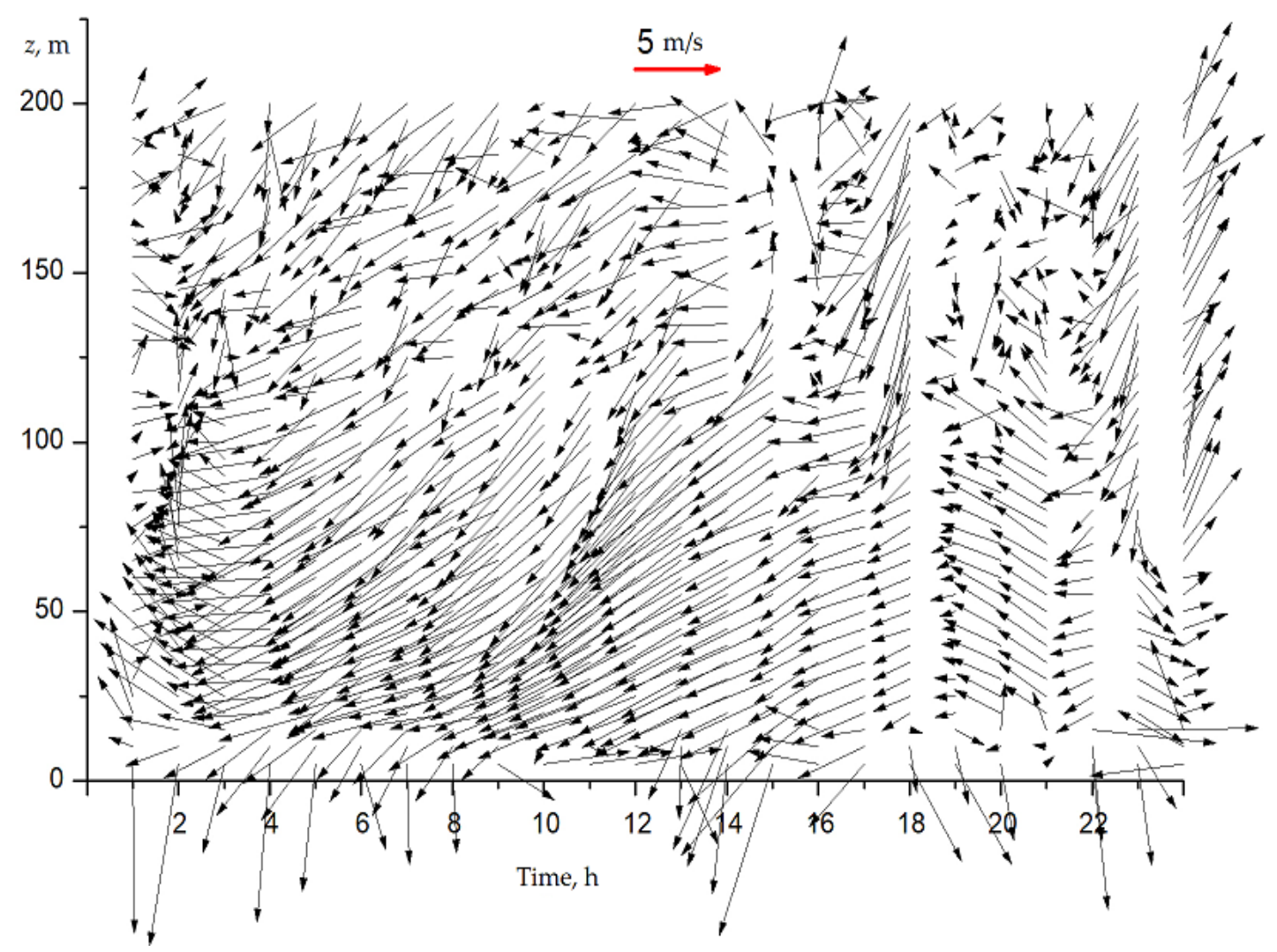

Fig. 3. Daily hourly dynamics of the wind velocity in the vector representation (northern direction - upward, southern-- downward, east - to the right, and west - to the left) from minisodar measurements on September 16 with 10 -min averaging. The wind scale is indicated above the figure.

Note also that in the daytime (from 10:00 till 17:00), the values of the average horizontal velocity component significantly exceeded their corresponding evening values (from 18:00 till 23:00). In this case, the values of the average horizontal wind velocity were maximum in the daytime from 10:00 till 16:00-17:00 and minimum late in the evening and at night from 20:00 till 23:00.

The turbulent kinetic energy component is expressed in terms of the standard deviations $\sigma_{x}, \sigma_{y}$, and $\sigma_{z}$ of the wind vector components. Figure 4 illustrates the diurnal behavior (in 3 hours) of the standard deviations of the wind vector components averaged over 10-min periods from minisodar measurements on September 16-17.

From Fig. 4 it can be seen that $\sigma_{x}$ and $\sigma_{y}$ weakly depended on the altitude up to $\sim 100 \mathrm{~m}$ and started to increase at higher altitudes, and $\sigma_{z}$, vice versa, first increased with altitude up to $z=50 \mathrm{~m}$ and then weakly depended on the altitude with its further increase. It can also be seen that the main contribution to the turbulent kinetic energy component comes from the $x$ - and $y$-components, since the values of the standard deviations of the $z$-component are much lower. 

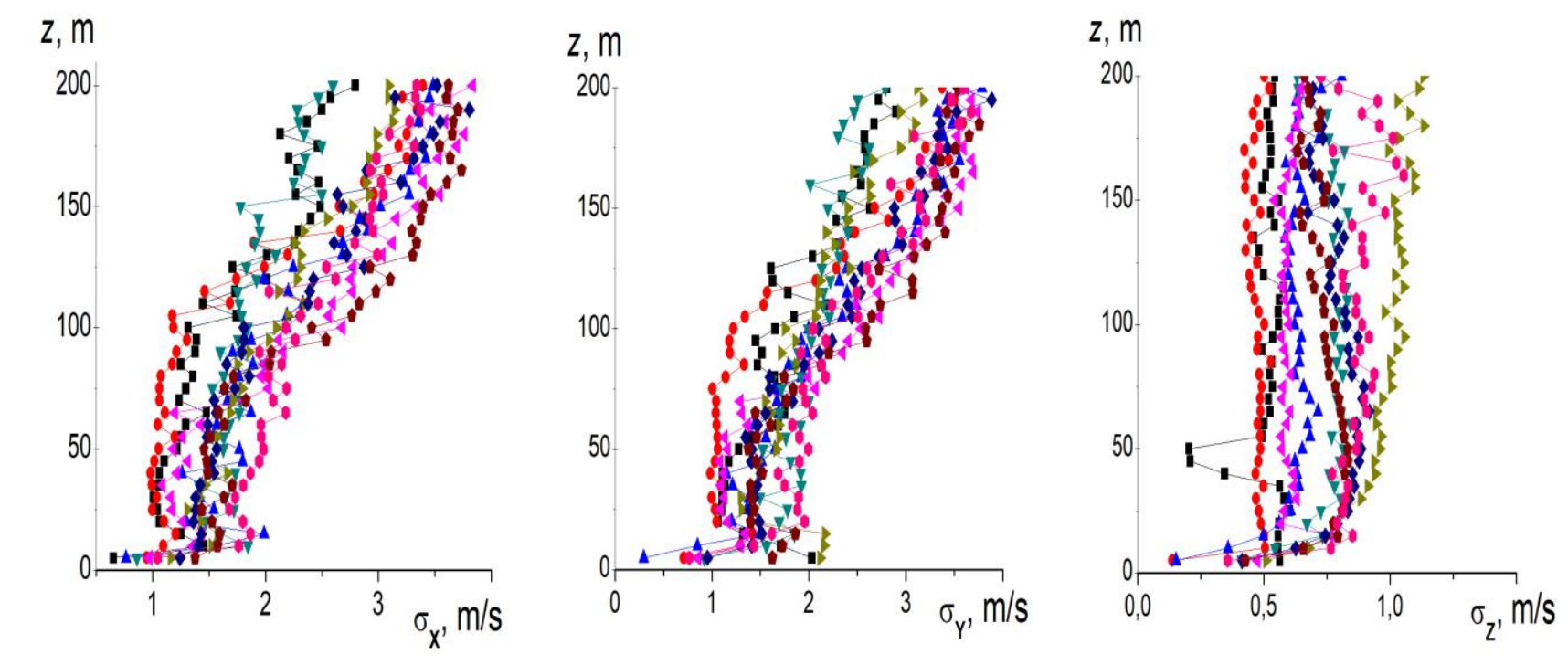

- $10: 00 \longrightarrow 13: 00 \simeq 16: 00$
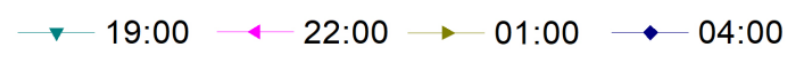

$-07: 00$

$10: 00$

Fig. 4. Diurnal dynamics (in 3 hours) of the standard deviations of the wind vector components averaged over 10-min periods retrieved from minisodar measurements on September 16-17.

\section{Conclusions}

The total kinetic energy of the atmosphere and its components have been estimated from minisodar measurements of the diurnal hourly dynamics of the wind vector components in the lower 5-200-meter layer of the atmosphere during 7 days, with a particular emphasis on the turbulent kinetic energy. To explain the special features of the spatiotemporal dynamics of the total kinetic energy, the spatiotemporal dynamics of the wind velocity field in the vector presentation and of the standard deviations of the wind velocity components were analyzed. Our analysis of the vertical profiles of the kinetic energy components has shown that in the lower atmospheric layer at altitudes up to $50 \mathrm{~m}$, the values and the spread of the turbulent kinetic energy component $E$ тКЕ were low; they linearly increased at higher altitudes. In the morning, the contribution of the mean kinetic energy in the lower 100-meter layer of the atmosphere exceeded the contribution of the turbulent kinetic energy. The vertical profile of the MKE increased in the morning, reached its maximum values by noon, and then decreased toward midnight. During observations, the turbulent energy reduced to unit air mass changed from several units to several hundreds $\mathrm{of} \mathrm{m}^{2} / \mathrm{s}^{2}$. The diurnal behavior of the kinetic energy was characterized by the presence of several minima and maxima, the time of occurrence and the values of which depended on the meteorological conditions of observations and the solar radiation intensity. At altitudes above $100 \mathrm{~m}$, the maximum TKE and MKE values were observed in the evening (at 18:00) and at midnight (at 00:00). The maximum values of the turbulent kinetic energy were recorded at altitudes of 150-200 m.

From the diurnal hourly altitude profiles of the turbulent kinetic energy values retrieved from minisodar data, four layers have been established by the character of the altitude TKE dependence, namely, the near-ground layer, the surface layer, the layer with linear TKE increase, and the transitive layer above. In the first layer, the most significant changes of the TKE were observed in the evening hours. In the second layer, no significant changes in the TKE values were observed. The linear increase of the TKE values with altitude was observed in the third layer. In the fourth layer, the TKE slightly increased with altitude and exhibited variations during the entire observation period. The altitudes of the upper boundaries of these layers depended on the time of day. The MKE values were much less than the corresponding TKE values. If the MKE values reached and even exceed $200 \mathrm{~m}^{2} / \mathrm{s}^{2}$ (for example, at 00:00, from 05:000 till 14.00, and from 17.0 till 22.0), the MKE values, as a rule, hardly reached $50-70 \mathrm{~m}^{2} / \mathrm{s}^{2}$ (for example, at 00:00, from 13:00 till 15:00, and at 18:00).

From two to four MKE layers were distinguished based on the character of its altitude dependence. The twolayer structures were observed in the evening and at night. In the morning and daytime, the four-layer MKE structures with the additional second and third layers of a linear increase and subsequent decrease of the MKE values were established. It should be noted that a case study of the stable atmospheric boundary layer with a coherent Doppler wind lidar in [8] also demonstrated that the stable atmospheric boundary layer has the inhomogeneous 
layered structure. Our estimates demonstrated that the TKE contribution to the total kinetic energy considerably (by a factor of 2.5-3) exceeded the corresponding MKE contribution.

Author Contributions: Conceptualization, A.P., L.Sh., and V.K.; methodology, A.P., L.Sh., and V.K.; software, A.P., L.Sh., and V.K.; validation, A.P., L.Sh., and V.K.; formal analysis, A.P. L.Sh., and V.K.; investigation, A.P., L.Sh., and V.K.; resources, A.P., L.Sh., and V.K.; data curation, A.P., L.Sh., and V.K.; writing-original draft preparation, A.P., L.Sh., and V.K.; writing-review and editing, A.P., L.Sh., and V.K.; visualization, A.P., L.Sh., and V.K.; supervision, A.P., L.Sh., and V.K.; project administration, A.P., L.Sh., and V.K.; funding acquisition, A.P., L.Sh., and V.K. All authors have read and agreed to the published version of the manuscript.

Conflicts of Interest: The authors declare no conflict of interest.

\section{References}

1. Lundquist J.K., Clifton A., Dana S., Huskey A., Moriarty P., van Dam J, and Herges T. Wind Energy Instrumentation Atlas. Golden, CO: National Renewable Energy Laboratory. NREL/TP-5000-68986, 2019; https://www.nrel.gov/docs/fy19osti/68986/pdf.

2. Sutton O. G. Micrometeorology: A Study of Physical Processes in the Lowest Layers of the Earth's Atmosphere, McGraw Hill, New York; 1953; 333pp.

3. Haggagy M.E. A Sodar-Based Investigation of the Atmospheric Boundary Layer, Berichte des Meteorologischen Institutes des Universität Freiburg, 2003, No. 8, 235 pp.

4. Debnath M. and Coauthors, Assessment of virtual towers performed with scanning wind lidars and Ka-band radars during the XPIA experiment, Atmos. Meas. Tech., 2017, 10, pp. 1215-1227; DOI 10.5194/amt-10-1215-2017.

5. Courtney M., Wagner R., and Lindelöw P., Commercial lidar profilers for wind energy. A comparative guide. In Proc. EWEC 2008, 2008; https:/www.renewablenrgsystems.com/assets/resources/Commercial-Lidar-Profilers-for-WindEnergyWhitepaper.

6. Emeis S. Wind Energy Meteorology: Atmospheric Physics for Wind Power Generation; Springer Science \& Business Media, 2012; 202 pp.

7. Emeis S. Surface-Based Remote Sensing of the Atmospheric Boundary Layer; Springer Science \& Business Media; $2010 ; 181$ pp.

8. Banakh Victor A., Smalikho Igor N. and Falits Andrey V., Wind-temperature regime and wind turbulence in a stable boundary layer of the atmosphere: Case study, Remote Sensing, 2020, 12, 955; doi: 10.3390/rs12060955.

9. Zhhiyong Wang, Lanqiang Zhang, Changhui Rao. Characterizing daytime wind profiles with the wide-field ShackHartmann wavefront sensor, 2019, Monthly Notices of the Royal Astronomical Society, 483, pp. 4910-4921; https://doi.org/10.1093/mnras/sty3417.

10. Andrés Guesalaga, Benoit Neichel, Angela Cortés, Clémentine Béchet, Dani Guzman. Using the $C_{n}^{2}$ and wind profiler method with wide-field laser-guide-stars adaptive optics to quantify the frozen-flow decay, 2014, Monthly Notices of the Royal Astronomical Society, 440, pp. 1925-1933; https://doi.org/10.1093/mnras/stu366.

11. Shikhovtsev A.Y., Kiselev A.V., Kovadlo P.G., Kolobov D.Y., Lukin V.P., Tomin V.E. Method for estimating the atmospheric layers with strong turbulence, 2020, Atm. Ocean. Opt., 33, No. 3, pp. 295-301.

12. Doppler MiniSoDAR System. Operation and Maintenance Manual, 2008, Atmospheric Systems Corporation; 44 pp.

13. Bradley S., Atmospheric Acoustic Remote sensing; CRC Press, Taylor \& Francis Group, LLC, Boca Raton; London; New York; 2008; 265 pp.

14. Shamanaeva L.G., Potekaev A.I., Krasnenko N.P. Kapegesheva O.F. Dynamics of the kinetic energy in the atmospheric boundary layer from the results of minisodar measurements. Russ. Phys. J. 2018, 61, pp. 2282-2287; DOI 10.1007/s11182019-01668-1.

15. Liudmila G. Shamanaeva, Aleksandr I. Potekaev, Valentina V. Kalugina, Diurnal dynamics of the reduced turbulent kinetic energy in the atmospheric boundary layer from minisodar measurements, Sciforum Electronic Conference Series, Vol. 3, Article ID: sciforum-038292, 6 pp. (2020).

16. Simakhin V.A., Cherepanov O.S., Shamanaeva L.G. Censoring of samples of minisodar wind velocity measurements using a modified pendulum truncation method. In Proc. SPIE 11208, $5^{\text {th }}$ International Symposium on Atmospheric and Ocean Optics: Atmospheric Physics, 1120872 (2019); https://doi.org/10.1117/12.254030.

17. Taresenkov Mikhail Viktorovich, Krasnenko Nikolai Petrovich, Shamanaeva Liudmila Grigor'evna. RF Certificate of State Registration of Computer Program No. 2016619428 "Program for constructing the altitude-temporal distribution of wind velocity components in the lower atmosphere from the data of acoustic sounding", Date of State Registration in the Register of Computer Programs August 18, 2016.

18. Underwood K.H., Shamanaeva L.G. Turbulence characteristics from minisodar data. Russ. Phys. J. 2010, 53, pp. 526-532. 